\title{
The Facioscapulohumeral muscular dystrophy region on 4qter and the homologous locus on IOqter evolved independently under different evolutionary pressure
}

\author{
Monica Rossi ${ }^{1,3}$, Enzo Ricci ${ }^{1,2}$, Luca Colantoni², Giuliana Galluzzi², \\ Roberto Frusciante ${ }^{1}$, Pietro A Tonali ${ }^{1,3}$ and Luciano Felicetti*1,3
}

\begin{abstract}
Address: ${ }^{1}$ Department of Neuroscience, Institute of Neurology, Catholic University of Sacred Heart, L.go A. Gemelli 8, 00168 Rome, Italy, ${ }^{2}$ Center for Neuromuscular Diseases, UILDM, Via Prospero Santacroce, 5, 00167 Rome, Italy and ${ }^{3}$ Fondazione Don Carlo Gnocchi, Via Maresciallo Caviglia, 30, 00194 Rome, Italy

Email: Monica Rossi - m.rossi@rm.unicatt.it; Enzo Ricci - ericci@rm.unicatt.it; Luca Colantoni - l.colantoni@hsantalucia.it;

Giuliana Galluzzi -g.galluzzi@hsantalucia.it; Roberto Frusciante - roberto.frusciante@rm.unicatt.it; Pietro A Tonali - ptonali@rm.unicatt.it;

Luciano Felicetti* - lfelicetti@ciaoweb.it

* Corresponding author
\end{abstract}

Published: 2 March 2007

BMC Medical Genetics 2007, 8:8 doi:10.1 186/147/-2350-8-8

This article is available from: http://www.biomedcentral.com/I47I-2350/8/8

(c) 2007 Rossi et al; licensee BioMed Central Ltd.

This is an Open Access article distributed under the terms of the Creative Commons Attribution License (http://creativecommons.org/licenses/by/2.0), which permits unrestricted use, distribution, and reproduction in any medium, provided the original work is properly cited.

\begin{abstract}
Background: The homologous $4 q$ and $10 q$ subtelomeric regions include two distinctive polymorphic arrays of $3.3 \mathrm{~kb}$ repeats, named D4Z4. An additional BInl restriction site on the 10q-type sequence allows to distinguish the chromosomal origin of the repeats. Reduction in the number of D4Z4 repeats below a threshold of 10 at the $4 q$ locus is tightly linked to Facioscapulohumeral Muscular Dystrophy (FSHD), while similar contractions at 10q locus, are not pathogenic. Sequence variations due to the presence of Blnl-sensitive repeats (IOq-type) on chromosome 4 or viceversa of Blnl-resistant repeats (4q-type) on chromosome 10 are observed in both alleles.
\end{abstract}

Results: We analysed DNA samples from 116 healthy subiects and II 4 FSHD patients and determined the size distributions of polymorphic $4 q$ and $10 q$ alleles, the frequency and the D4Z4 repeat assortment of variant alleles, and finally the telomeric sequences both in standard and variant alleles.

We observed the same frequency and types of variant alleles in FSHD patients and controls, but we found marked differences between the repeat arrays of the $4 q$ and $10 q$ chromosomes. In particular we detected $10 q$ alleles completely replaced by the $4 q$ subtelomeric region, consisting in the whole set of $4 q$-type repeats and the distal telomeric markers. However the reciprocal event, I0q-type subtelomeric region on chromosome 4, was never observed. At $4 q$ locus we always identified hybrid alleles containing a mixture of $4 q$ and $10 q$-type repeats.

Conclusion: The different size distribution and different structure of $10 q$ variant alleles as compared with $4 q$ suggests that these loci evolved in a different manner, since the $4 q$ locus is linked to FSHD, while no inheritable disease is associated with mutations in 10qter genomic region. Hybrid alleles on chromosome 4 always retain a minimum number of $4 q$ type repeats, as they are probably essential for maintaining the structural and functional properties of this subtelomeric region.

In addition we found: i) several instances of variant alleles that could be misinterpreted and interfere with a correct diagnosis of FSHD; ii) the presence of borderline alleles in the range of 30-40 kb that carried a qA type telomere and were not associated with the disease. 


\section{Background}

DNA repeats can be the source for an extraordinary amount of information about biological processes. As passive markers they provide clues for evolutionary events and processes of mutation and selection, as active agents repeats have remodeled the genome by causing ectopic rearrangements, by creating entirely new genes and by modifying and reshuffling existing genes. Specifically, segmental duplications involve the transfer of 1-200 kb blocks of genomic sequences to one or more locations in the genome and may contain various types of repeats [1]. These transfers have been shown to occur between homologous and non-homologous chromosomes [2,3]; their preference for pericentromeric and subtelomeric sites can be explained by a damage-control mechanism that facilitates insertion of chromosomal breakage products into poor-gene regions $[4,5]$. A particular case of interchromosomal duplication is that observed at the subtelomeric $4 \mathrm{q} 35$ and 10q26 loci [6]. The sequence homology between these subtelomeric regions is very high (nearly $99 \%$ ) and is not restricted to a polymorphic array of 3.3 kb KpnI repeat units, designated D4Z4, but continues distally for at least $6 \mathrm{~kb}$ and proximally for nearly $42 \mathrm{~kb}[7,8]$. The reduction in the number of $3.3 \mathrm{~kb}$ D4Z4 repeat to an array of 1-10 units at the $4 \mathrm{q} 35$ locus is tightly linked to FSHD, an autosomal-dominant myopathy with an estimated prevalence of $1 / 20.000$ [9]. Similar contractions involving 10q26 D4Z4 repeats are not pathogenic. In normal subjects the single copy probe $\mathrm{p} 13 \mathrm{E}-11$ reveals polymorphic EcoRI fragments in the range 40 to $300 \mathrm{~kb}$ including the repeat array, whereas in sporadic and familial cases of FSHD the disease cosegregates with a EcoRI shorter fragment ranging between 10 and $40 \mathrm{~kb}$ [10-12]. The identification of a BlnI restriction site within each 10q repeat unit that is absent in the homologous $4 \mathrm{q}$ repeat [13] and the use of pulsed field gel electrophoresis (PFGE) allows to distinguish between the p13E-11 fragments of $4 \mathrm{q}$ and $10 \mathrm{q}$ origin, to study their number and size and to detect sequence exchanges between the two loci $[14,15]$. A high number of variant alleles has been detected in human population and is probably consistent with the occurrence of rearrangements between $4 \mathrm{q}$ and $10 \mathrm{q}$ homologous subtelomeric regions, even if the "de novo" translocation events were never detected. Sequence variations consist in the presence of BlnI-sensitive repeats (10q-type) on chromosome 4 or vice versa of BlnI-resistant repeats (4q-type) on chromosome 10. These exchanges were found in $20-30 \%$ of normal subjects and caused either a reduction of the number of BlnI-resistant fragments or an increase of the number of BlnI-resistant fragments in the genome [15], interfering with the correct assignment of DNA fragments to a specific chromosome pair and with an accurate genetic diagnosis of the FSHD [16]. Moreover in healthy individuals a biallelic variation was identified at the $4 \mathrm{q}$ region distal to D4Z4, named qA type and $\mathrm{qB}$ type. In FSHD patients the contracted D4Z4 fragments implicated in the disease are exclusively located on $4 \mathrm{q}$ alleles of qA type, while the $10 \mathrm{q}$ alleles always have a qA type telomere $[17,18]$.

In this paper we performed a detailed analysis of $4 \mathrm{q}$ and $10 \mathrm{q}$ subtelomeric regions by characterizing the D4Z4 repeat assortment and the distal telomeric markers in Italian healthy subjects and FSHD patients, thus extending previous studies in other populations. We determined: i) the size distribution of polymorphic $4 \mathrm{q}$ alleles as compared with $10 \mathrm{q}$ alleles; ii) the frequency of variant $4 \mathrm{q}$ and $10 \mathrm{q}$ alleles; iii) the D4Z4 repeat assortment of $4 \mathrm{q}$ and $10 \mathrm{q}$ variant alleles; and finally; iv) the $\mathrm{qA}$ and $\mathrm{qB}$ telomeric sequences both in standard and variant alleles.

\section{Methods}

Patients and controls Diagnostic criteria for FSHD followed the guidelines proposed by the European Expert Group on FMD [19]. Neurological examinations of 70 unrelated FSHD families for a total of 230 individuals (116 affected and 114 unaffected) were performed at Institute of Neurology of Catholic University of Rome and at the Centre for Neuromuscular diseases, U.I.L.D.M., Rome. For each FSHD family we chose only the proband, both for the study of size distribution of $4 \mathrm{q}-10 \mathrm{q}$ alleles and the types of variant arrays. Healthy subjects were chosen among hospital and laboratory staff as well among the spouses of FSHD families (genetically unrelated to FSHD patients) for a total of 106 individuals. DNAs were obtained from healthy subjects and patients after informed consent in agreement with the guidelines of the Ethical Committee of our Institution.

\section{Lymphocytes isolation from whole blood}

Lymphocytes were isolated from peripheral blood sample, embedded in 0.5\% Low Melt Agarose (Bio-Rad, Hercules, CA, USA) plugs and incubated with 0.5M EDTA, 1\% Sarcosyl (Sigma, St Louis, MO, USA) and $1 \mathrm{mg} / \mathrm{ml}$ Proteinase $\mathrm{K}$ for $24-48$ hrs at $50^{\circ} \mathrm{C}$ (Roche, Mannheim, Germany), according to the procedure described by Pharmacia.

\section{Restriction endonuclease digestion of DNA in agarose blocks and PFGE}

$1 / 4$ of plug, corresponding to $0.5 \times 10^{6}$ cells, was digested with the following restriction enzymes: EcoRI (Roche, Mannheim, Germany), BlnI (Amersham Pharmacia Biotech, Buckingamshire, U.K.) and XapI (Fermentas). Single (EcoRI, XapI) and double digestions (EcoRI/BlnI) were performed with 60/150 U of enzyme added in three equal portions, at $1 \mathrm{~h}$ intervals and incubated overnight.

PFGE was performed at $10^{\circ} \mathrm{C}$ in a Pulsaphor Electrophoresis unit with HEX electrode (Pharmacia LKB). High 
Strength Analytical Grade Agarose (Bio-Rad, Hercules, CA, USA) was used to prepare $1.2 \%$ gel in 0.5 tris-borateEDTA. The running procedure was performed at $300 \mathrm{~V}$ in 4 cycles: the first cycle was $1 \mathrm{~h} \mathrm{30}$ ' with pulse of $0.3 \mathrm{~s}$; the second was $3 \mathrm{~h} \mathrm{30'}$ with pulse of $0.5 \mathrm{~s}$, the third was $4 \mathrm{~h}$ with pulse of $1 \mathrm{~s}$ and the fourth was $2 \mathrm{~h} \mathrm{30}$ ' with pulse of 5 s [20].

\section{Southern Blot analysis}

After electrophoresis the DNA was transferred to Nylon membrane Hybond N+ (Amersham Pharmacia Biotech, Buckingamshire, U.K.) for hybridization. The probes were labelled by random priming with $\left[\alpha_{-}{ }^{32} \mathrm{P}\right] \mathrm{ATP}$ using the Multiprime DNA labeling system (Amersham Pharmacia Biotech, Little Chalfont, UK). Both the single copy p13E11 probe and the KpnI repeat sequence were obtained from $4.9 \mathrm{~kb}$ KpnI fragment subcloned in pUC21 [21]. For the KpnI probe we used the 1.179 bp fragment derived from BamHI digestion of the $3.3 \mathrm{~kb} \mathrm{KpnI}$ repeat. Hybridizations were performed overnight at $42^{\circ} \mathrm{C}$ in a hybridization mixture containing 50\% deionized Formamide, $3 \times$ SSC, $5 \times$ Denhardt's, $200 \mu \mathrm{g} / \mathrm{ml}$ Salmon Sperm and 10\% Dextran Sulfate. The membranes were washed in $2 \times$ SSC at room temperature and then in $0.5 \times$ SSC/0.1\%SDS at $58^{\circ} \mathrm{C}$. Labelling and hybridization with D4S139 of digested genomic DNA were performed as previously described [21].

\section{$q A$ and $q B$ telomeric markers}

To perform the allele-typing for $\mathrm{qA}$ and $\mathrm{qB}$, the DNA of healthy and affected subjects was digested with HindIII restriction enzyme (Roche Mannheim, Germany) (Fig. 1). The fragments were separated with PFGE, transferred to a Nylon membrane and hybridized with probes $\mathrm{qA}$ and $\mathrm{qB}$, supplied by S. M. van der Maarel [17]. The hybridizations were performed overnight at $60^{\circ} \mathrm{C}$ in a mixture containing $0.125 \mathrm{M} \mathrm{Na}_{2} \mathrm{HPO}_{4}(\mathrm{pH} \mathrm{7.2)}, 0.25 \mathrm{M} \mathrm{NaCl}, 1 \mathrm{mM}$ EDTA and $7 \%$ SDS. The membranes were washed in $2 \times$ SSC at $42^{\circ} \mathrm{C}$ and then in $0.1 \times$ SSC and $0.1 \%$ SDS at $65^{\circ} \mathrm{C}$ for 15 minutes.

\section{Statistical analysis}

The mean values of $4 \mathrm{q}$ and $10 \mathrm{q}$ allele sizes derived from healthy and FSHD subjects were compared using MannWhitney U-test and T-student test. The size distribution of $4 \mathrm{q}$ and $10 \mathrm{q}$ polymorphic fragments showed a bimodal distributions when divided into $20 \mathrm{~kb}$ classes. Upon visual inspection of the distribution we decided to partition each of them in 2 clusters. Cluster centers and number of chromosomes falling in each cluster were obtained with the program Quickcluster as implemented in SPSS v. 6.0.
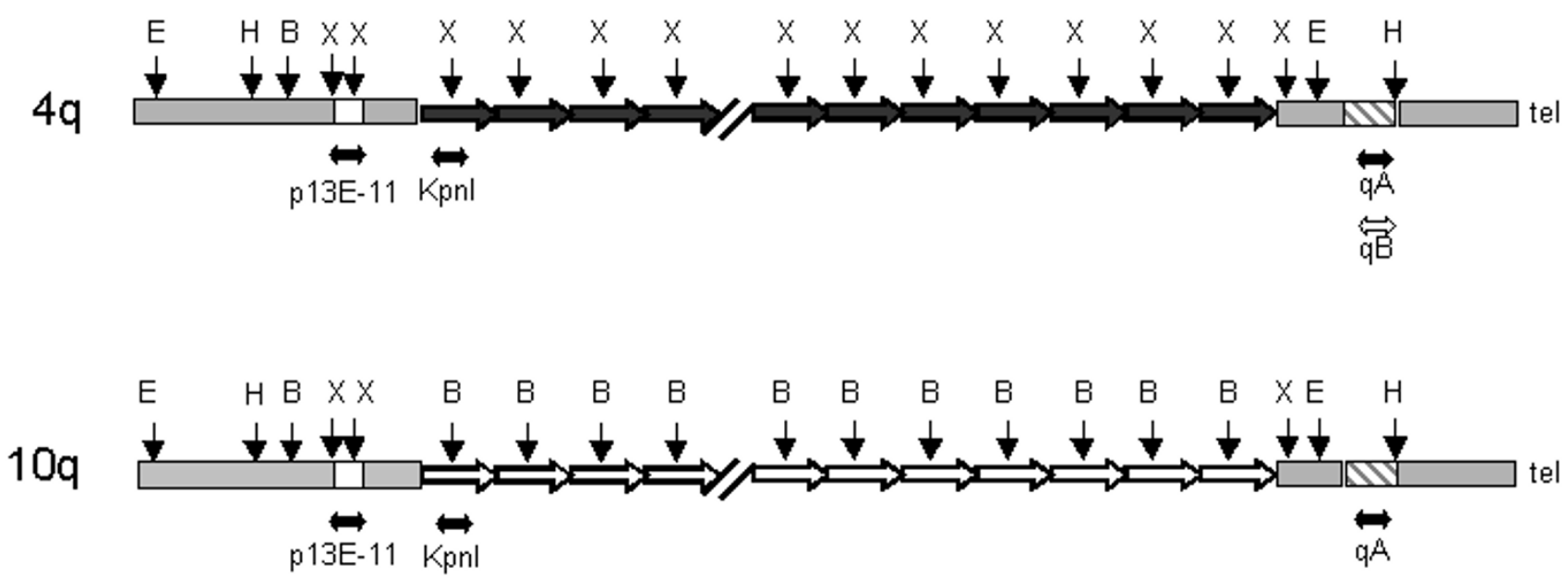

$B=B \ln I \quad E=E \operatorname{coRI} \quad H=H$ ind III $X=X a p I$

Figure I

$4 q$ and $10 q$ subtelomeric region. Positions of DNA probes and restriction enzymes utilized in the study are indicated. 


\section{Results \\ Canonical and non canonical pattern of $4 \mathrm{q}$ and I $0 \mathrm{q}$ alleles in human subjects}

We defined an individual as carrying a canonical pattern of alleles when, after PFGE analysis and hybridization with p13E-11 probe, we observed four restriction fragments with EcoRI and only two restriction fragments after double digestion EcoRI/BlnI: the alleles of $10 \mathrm{q}$ origin containing BlnI sensitive repeats were converted into $2.8 \mathrm{~kb}$ fragments and run out of the gel, while the alleles of $4 \mathrm{q}$ origin containing BlnI-resistant repeats were preserved and reduced by $3 \mathrm{~kb}$ due to a single BlnI restriction site 3 $\mathrm{kb}$ distal to the proximal EcoRI restriction site (Fig. 1). We defined an individual as carrying a non canonical pattern of alleles when the number of BlnI-resistant fragments are different from two (nullisomy, monosomy, trisomy, tetrasomy) $[15,20]$.

\section{Size distribution of $4 q$ and $10 q$ alleles} Healthy individuals (Fig. 2a)

Only $67 \%$ of 106 healthy subjects showed, after p13E-11 hybridization, a canonical pattern of alleles (Tab. 1). In these individuals the size of $4 \mathrm{q}$ alleles ranged between 30 and $200 \mathrm{~kb}$ (mean $90.68 \pm 42.84$ ) and displayed a bimodal distribution, with a larger peak at mean values of 80 $\mathrm{kb}$ and a smaller peak at $160 \mathrm{~kb}$. The size of $10 \mathrm{q}$ alleles ranged between 10 and $250 \mathrm{~kb}$ (mean $74.36 \pm 41.88$ ). The difference in size distribution of $4 \mathrm{q}$ and $10 \mathrm{q}$ alleles was significant ( $\mathrm{p}=0.002$ by $\mathrm{T}$ Student test and $\mathrm{p}=0.0006$ by Mann-Whitney test), as previously reported by Wijmenga et al. [22].

\section{FSHD familial cases (Fig. 2b)}

Among 70 FSHD probands, $73 \%$ showed a canonical patterns. The mean value of the sizes of the $4 \mathrm{q}$ alleles not implicated in the disease was $76.73 \pm 33.90 \mathrm{~kb}$, significantly lower than that found in the controls carrying a pair of wild-type $4 \mathrm{q}$ alleles ( $\mathrm{p}=0.037$ by T Student test and $\mathrm{p}$ $=0.042$ by Mann-Whitney test). This result was in contrast with the even distribution of the size of $10 \mathrm{q}$ alleles in both healthy and affected subjects. The mean value of the size of the disease- related allele was $25.12 \pm 5.37 \mathrm{~kb}$.

\section{$q A$ and $q B$ Telomeric markers}

A biallelic variation, named $\mathrm{qA}$ and $\mathrm{qB}$ type, was identified at $4 \mathrm{q}$ telomeric region distal to $\mathrm{D} 4 \mathrm{Z} 4$ [17]. We analysed the telomeric sequences (qA/qB allele-typing) of 66 healthy and 40 FSHD individuals of our groups (see Methods) and reported the results in table 3. In FSHD patients the small $4 \mathrm{q}$ alleles linked to the disease were exclusively of A type, in agreement with the results obtained in the Dutch population [17]. Since qA alleles were reported to be on the average longer than $\mathrm{qB}$ alleles [23], the overrepresentation of qA telomeres in our control population could explain the higher mean value of $4 \mathrm{q}$ allele sizes in healthy subjects compare to FSHD patients (Tab. 2).

Among healthy subjects we observed two $4 \mathrm{q}$ alleles of 33 and $38 \mathrm{~kb}$ (Fig. 2a). They showed telomeric sequences of qA type. Furthermore we described four affected individuals carrying two $4 \mathrm{q}$ alleles shorter than $40 \mathrm{~kb}$ : in each case one $4 \mathrm{q}$ allele was FSHD-linked, the other was also present in healthy members of the family. Among the $4 \mathrm{q}$ short alleles not linked to the disease two of them of 30 and 37 $\mathrm{kb}$ had qB type telomeres (Fig. 3), the other two of 33 and $38 \mathrm{~kb}$ had qA type telomeres. The proband carrying the allele of $33 \mathrm{~kb}$ also had a FSHD-linked 4q of $29 \mathrm{~kb}$ (qA) and the proband carrying the allele of $38 \mathrm{~kb}$ had a FSHDlinked $4 \mathrm{q}$ of $26 \mathrm{~kb}$ (qA). The phenotype of both probands were compatible to the length of their FSHD-linked $4 \mathrm{q}$ [12]. We did not observe relevant differences between the clinical phenotype of these patients carrying both $4 \mathrm{qA}$ alleles shorter than $40 \mathrm{~kb}$ and the other affected members of the families. Since the phenotypic expression of FSHD is extremely variable both within and between families, our two cases are not sufficient to confirm or reject the theory of dosage effect in FSHD patients [24].

\section{$4 q$ and IOq allelic patterns in healthy subjects and FSHD patients}

In healthy individuals we found a change in the disomic pattern of alleles in 35 cases (33\%): 10 (9\%) were trisomic, 16 (15\%) monosomic and 7 (7\%) displayed more complex rearrangements (Tab. 1). Finally, in 2 individuals, we found only three EcoRI restriction fragments, suggesting a deletion that involves $\mathrm{p} 13 \mathrm{E}-11$ sequences. In the first individual we did not find any residual D4Z4 repeats on $4 \mathrm{q}$, in agreement with the observation that cytogenetic deletions encompassing p13E-11 and the whole set of D4Z4 repeats are not pathogenic. It is generally accepted that at least one KpnI repeat is required for the development of the disease $[25,26]$. In the other case hybridization with KpnI probe detected a BlnI resistant fragment of $120 \mathrm{~kb}$, corresponding to a residual array of $35 \mathrm{D} 4 \mathrm{Z4}$ repeats. The presence of a number of D4Z4 above the threshold number of 10 does not lead to the disease despite the deletion of p13E-11 sequence.

Among the 70 FSHD probands we found that $73 \%$ carried a canonical pattern of alleles (Tab. 1), the remaining subjects $(27 \%)$ displayed different kinds of variant alleles giving origin to a pattern of trisomy in 12 patients $(17 \%)$, monosomy in $5(7 \%)$ and nullisomy in one of them (Fig. 4).

\section{Analysis of structural organization of variant $4 q$ and $10 q$ alleles in healthy and affected subjects}

After hybridization with p13E-11, the filters were stripped and re-hybridized with the multicopy KpnI probe (see Methods). If the $4 \mathrm{q}$ and $10 \mathrm{q}$ alleles were homogeneous in 
a)

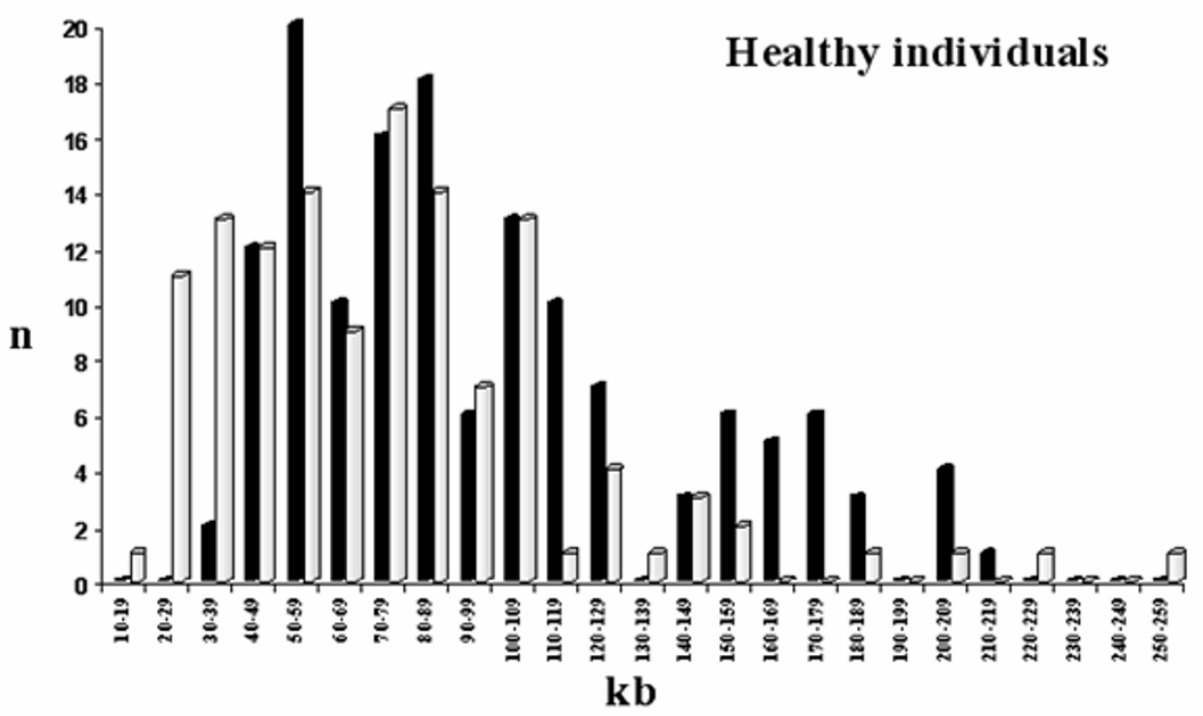

b)

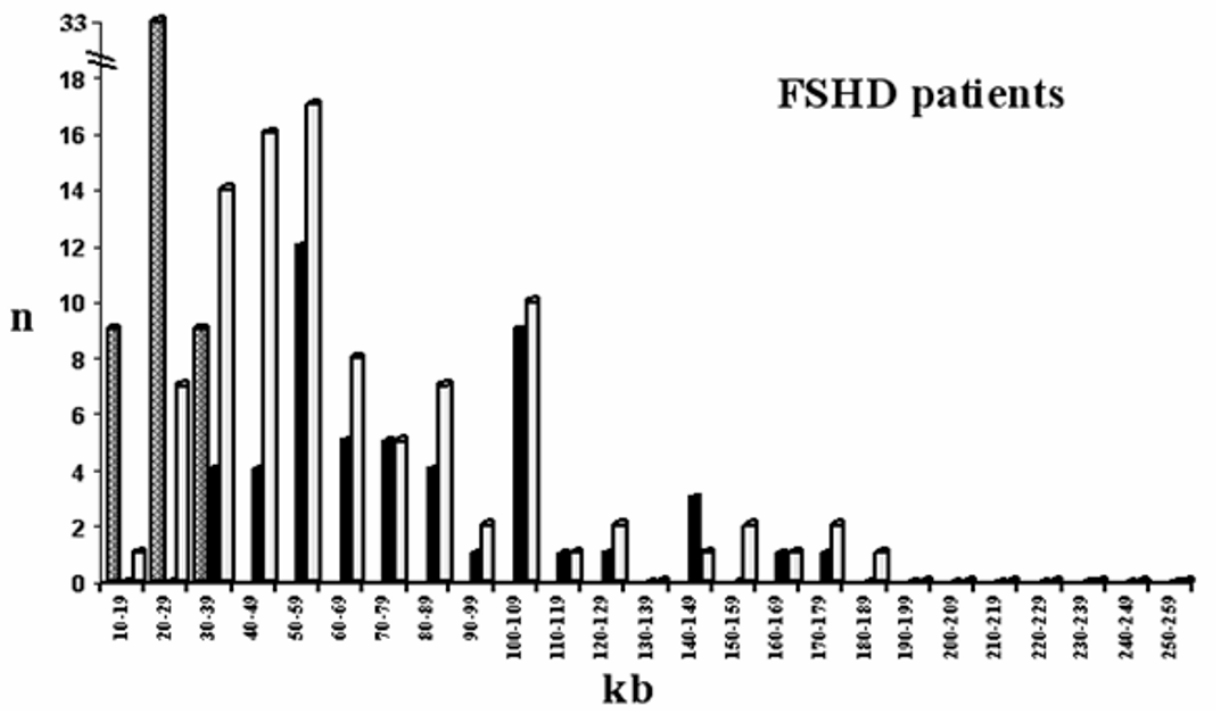

Figure 2

Size distribution of $4 \mathrm{q}$ and $\mathrm{IO} \mathrm{q}$ alleles in healthy and FSHD affected subjects. The size distributions of $4 \mathrm{q}$ and $\mathrm{IO} q$ alleles detected in healthy subjects (panel a) and FSHD patients (panel b) are represented. The size of EcoRI fragments is expressed in $\mathrm{kb}$, with $10 \mathrm{~kb}$ intervals. Black bars: $4 \mathrm{q}$ wild-type alleles; grey bars: disease-associated $4 \mathrm{q}$ alleles; white bars: $10 q$ alleles. 
Table I: Canonical and non canonical patterns in healthy subjects and FSHD patients

\begin{tabular}{lcc}
\hline & Healthy & FSHD \\
\hline - Canonical pattern & $71(\mathbf{6 7 \%})$ & $51(\mathbf{7 3} \%)$ \\
- Non canonical pattern & $35(\mathbf{3 3} \%)$ & $19(\mathbf{2 7 \% )}$ \\
Nullisomy & 0 & 1 \\
Monosomy & 16 & 5 \\
Trisomy & 10 & 12 \\
Tetrasomy & 0 & 0 \\
Complex rearrangements & 7 & 1 \\
p/3E-II deletions & 2 & 0 \\
\hline Total number & 106 & 70 \\
\hline
\end{tabular}

D4Z4 repeat constitution, KpnI hybridization confirmed the canonical pattern observed with p13E-11. On the contrary, if the 4q and 10q alleles had a non homogeneous repeat array, additional bands were observed after hybridization with KpnI (Fig. 4). The bands are stretches of BlnIresistant repeats separated from p13E-11 sequence by BlnI-sensitive repeats. We assigned the fragments to their original alleles through the study of the segregation with p13E-11 and D4S139 (4q specific) probes in the family. After that we reconstructed the repeat array assortment of the variant allele by subtracting the size of the BlnI-resistant band (observed with KpnI probe) from the length of the EcoRI band (observed with p13E-11 probe).

In more complex cases and where we could not study the allelic segregation in the family, we performed an additional Southern blot analysis with the DNA samples digested with the restriction enzyme XapI (Fig. 4). This enzyme shows the opposite characteristics to BlnI: XapI restriction sites are present in the 4q-type repeats and are absent in the 10q-type [27].

In conclusion we named as "standards" those allele in which both the $4 \mathrm{q}$ and $10 \mathrm{q}$ alleles carried a homogeneous, uninterrupted array of BlnI-resistant (4q-type) or BlnI-sensitive (10q-type) repeats, respectively (Fig. 1). We defined as "variants" those $4 \mathrm{q}$ and $10 \mathrm{q}$ alleles with different assortment of D4Z4 repeats. Among variant alleles we detected hybrid types (alleles with a mixture of 4q-type and $10 \mathrm{q}$ type repeats) and homogeneous types.

In healthy subjects we analysed a total number of 212 alleles of either $4 \mathrm{q}$ or $10 \mathrm{q}$ types and identified $194 \mathrm{q}$ variant alleles (9\%) and 13 10q variant alleles (6\%) (Tab. 3).

A similar frequency was observed in the affected individuals: among the 140 alleles analysed, 8 variant $4 \mathrm{q}(6 \%)$, and 13 variant 10q (9\%) alleles were encountered (Tab. 3).

In figure 5 we described the $4 \mathrm{q}$ and $10 \mathrm{q}$ variant alleles in which we could reconstruct the D4Z4 repeat assortment. Since family study or additional DNA samples for XapI digestions were not always available, we were not able to reconstruct the $\mathrm{D} 4 \mathrm{Z} 4$ repeat constitution of the variant alleles in all individuals. However we observed that even the $4 \mathrm{q}$ alleles not included in the diagram showed a stretch of BlnI-sensitive repeats followed by BlnI-resistant repeats, while all the $10 \mathrm{q}$ variant alleles carried an uninterrupted array of BlnI-resistant repeats.

$4 q$ variant alleles ( $10 q$ repeats on chromosome $4 q$ )

We observed BlnI-sensitive repeats upstream the BlnIresistant units on $4 \mathrm{q}$ chromosome in 26 out of 27 variant alleles (Fig. 5). Only one allele from a healthy subject showed 10q-type repeats into the terminal part of a $4 \mathrm{q}$ array: the $4 \mathrm{q}$ origin of the allele was confirmed by the segregation analysis using D4S139 probe. It is worth noting that in all cases the variant $4 \mathrm{q}$ alleles had a heterogeneous mixture of BlnI-resistant (4q-type) and BlnI-sensitive (10q-type) D4Z4 repeat units (Tab. 3).

Among FSHD patients we found one case in which the disease allele was hybrid and carried BlnI-sensitive repeats mimicking a $10 \mathrm{q}$ allele (allele n.16 Fig. 5).

The size of the variant $4 \mathrm{q}$ alleles ranged between 40 and $200 \mathrm{~kb}$ (corresponding to 10 and 60 repeat units) and there was no preferential involvement of a specific class of alleles. In 14 cases a small number of 10q-type repeats were present on $4 \mathrm{q}$ alleles (from 1 to 3 repeats). In 4 alleles (10-11-12-17) we found evidence of multiple clusters

Table 2: Typing of $q A$ and $q B$ telomeres of $4 q$ alleles from healthy subjects and FSHD patients

\begin{tabular}{|c|c|c|c|c|c|}
\hline \multicolumn{2}{|c|}{ Healthy subjects } & \multicolumn{2}{|c|}{ FSHD patients (normal allele) } & \multicolumn{2}{|c|}{ FSHD patients (short allele) } \\
\hline $4 q A$ & $4 q B$ & $4 q A$ & $4 q B$ & $4 q A$ & $4 q B$ \\
\hline 45 (68\%) & $21(32 \%)$ & $23(57 \%)$ & 17 (43\%) & $40(100 \%)$ & $0(0 \%)$ \\
\hline \multicolumn{2}{|c|}{ TOT: 66 alleles } & \multicolumn{2}{|c|}{ TOT: 40 alleles } & \multicolumn{2}{|c|}{ TOT: 40 alleles } \\
\hline
\end{tabular}


Table 3: Number and type of variant alleles in healthy subjects and FSHD patients

\begin{tabular}{|c|c|c|c|c|}
\hline & \multicolumn{2}{|c|}{ Chr. 4 alleles } & \multicolumn{2}{|c|}{ Chr. I 0 alleles } \\
\hline & Healthy & FSHD & Healthy & FSHD \\
\hline Total number of alleles & 212 & 140 & 212 & 140 \\
\hline Variant alleles (total) & $19(9 \%)$ & $8(6 \%) *$ & $13(6 \%)$ & $13(9 \%)$ \\
\hline $\begin{array}{l}\text { homogeneous Kpnl } \\
\text { array }\end{array}$ & 0 & 0 & 12 & II \\
\hline $\begin{array}{l}\text { heterogeneous Kpnl } \\
\text { array }\end{array}$ & 19 & 8 & 1 & 2 \\
\hline pI3E-I I deletion & 2 & 0 & 0 & 0 \\
\hline
\end{tabular}

*only one variant $4 q$ allele is disease-related

of BlnI-sensitive repeats interspersed within BlnI-resistant units.

$10 q$ variant alleles (4q repeats on chromosome $10 q$ )

In 25 out of 26 cases (96\%) BlnI-resistant D4Z4 repeats were detected on the $10 \mathrm{q}$ chromosome at the proximal level, close to the p13E-11 site (Fig. 5). In contrast to the heterogeneity of the $4 \mathrm{q}$ variant alleles, the $10 \mathrm{q}$ variant alleles were homogeneous in 23 cases ( $88 \%$ ) (Tab. 3). The set of 4q-type repeats on 10q chromosome was uninterrupted, only in 2 cases few BlnI-sensitive repeats were interspersed within BlnI-resistant arrays. Only in one case the 4q-type repeats were found in the terminal part of the $10 \mathrm{q}$ repeat array. The size of variant $10 \mathrm{q}$ alleles varied between 20 and $120 \mathrm{~kb}$ and the number of 4q-type repeats (ranging between 4 and 29) was higher than the number of 10q-type repeats observed on $4 \mathrm{q}$ variant alleles (ranging between 1 and 17).

\section{Telomeric markers}

We were interested to extend the study of qA and qB telomeric sequences to $4 \mathrm{q}$ and $10 \mathrm{q}$ variant alleles. We analysed twelve $4 \mathrm{q}$ variant alleles: nine of them showed an $\mathrm{A}$ type telomere, three a B type. Among the twelve $10 \mathrm{q}$ variant alleles studied carrying a homogeneous set of BlnIresistant repeats, eight were of A type and four of B type (Fig. 3 and Fig. 6), while standard 10q alleles always displayed A type telomeres.

\section{Conclusion}

The high level of sequence homology between the $4 \mathrm{q}$ and 10q loci would imply for both polymorphic regions a similar size distribution and recombination products. This is not the case: $10 \mathrm{q}$ alleles displayed a different size distribution as compared with $4 \mathrm{q}$ alleles with a high percentage of alleles shorter than $40 \mathrm{~kb}(18 \%)$. The differences are more evident when we analysed the structure of variant alleles. $4 \mathrm{q}$ variant alleles were heterogeneous and always contained a mixture of BlnI-sensitive (10q-type) and BlnI-resistant (4q-type) repeats, on the contrary 10q variant alleles usually displayed a homogeneous set of BlnI-resistant (4q-type) repeats. The variant alleles revealed that such interactions probably occurred in the past, but the different structures of $4 \mathrm{q}$ and $10 \mathrm{q}$ variant alleles support the idea that the exchanges between the two loci are rare and these subtelomeric regions appear to evolve independently under different evolutionary pressure. Since reduction in the number of $\mathrm{D} 4 \mathrm{Z} 4$ on $4 \mathrm{q}$ locus results in FSHD, it is not surprising that $4 \mathrm{q}$ chromosomes have incurred a strong selection pressure during human evolution. Gabellini et al. reported that a repressive protein complex binds a specific sequence within each D $4 \mathrm{Z} 4$ repeat unit on chromosome 4 . The reduction in the number of repeats in FSHD patients abolishes this binding and results in the loosening of the transcriptional repression at $4 \mathrm{q}$ region and in the overexpression of upstream genes (FRG2, FRG1, ANT1) [28,29]. Accordingly we observed that $4 \mathrm{q}$ type repeats are preserved on $4 \mathrm{q}$ chromosome as they are probably essential for maintaining the structural and functional properties of this subtelomeric region. In particular the distal repeats, close to $\mathrm{qA}$ and $\mathrm{qB}$ sequences, were always maintained on chromosome 4 .

Moreover we described $\mathrm{qB}$ telomeres on $10 \mathrm{q}$ variant alleles carrying homogeneous $4 \mathrm{q}$-type repeat arrays. This suggests that qB sequences are not exclusively associated with $4 \mathrm{q}$ chromosomes, but they are always linked to BlnIresistant repeats.

It was proposed that an ancestral duplication event generated $4 \mathrm{q}$ and $4 \mathrm{p}$ telomeric regions, then $4 \mathrm{q}$ sequences diverged and gave origin to a 4qA type telomere that was duplicated onto chromosome 10. A more recent duplication of telomeric sequences from $4 \mathrm{p}$ onto $4 \mathrm{q}$ gave origin to 4qB-type telomere [7]. Therefore the presence of qB on chromosome 10 demonstrates that a telomeric sequence exchange has occurred between the $4 \mathrm{qB}$ and $10 \mathrm{q}$ chromosomes after the duplication events.

We reported a detailed molecular analysis of the $10 \mathrm{q}$ and $4 \mathrm{q}$ subtelomeric regions in FSHD patients and controls with the aim of characterizing the D4Z4 repeat array assortment and the distal telomeric region (qA and $\mathrm{qB}$ ) of $4 \mathrm{q}$ and $10 \mathrm{q}$ alleles. We obtained new interesting findings about the structure of these subtelomeric regions that should be taken into account for a correct molecular diagnosis and genetic counseling of FSHD. In some cases the chromosome origin of the p13E-11 fragments could be misinterpreted: i) we found several $10 \mathrm{q}$ variant alleles with a BlnI-resistant array and a size smaller than $40 \mathrm{~kb}$ (Fig. 5) mimicking a FSHD-linked alleles; ii) in one patient we observed a 4q FSHD-linked allele carrying BlnI-sensitive repeats upstream the BlnI-resistant repeats, mimicking a 10q allele (Fig. 4). 

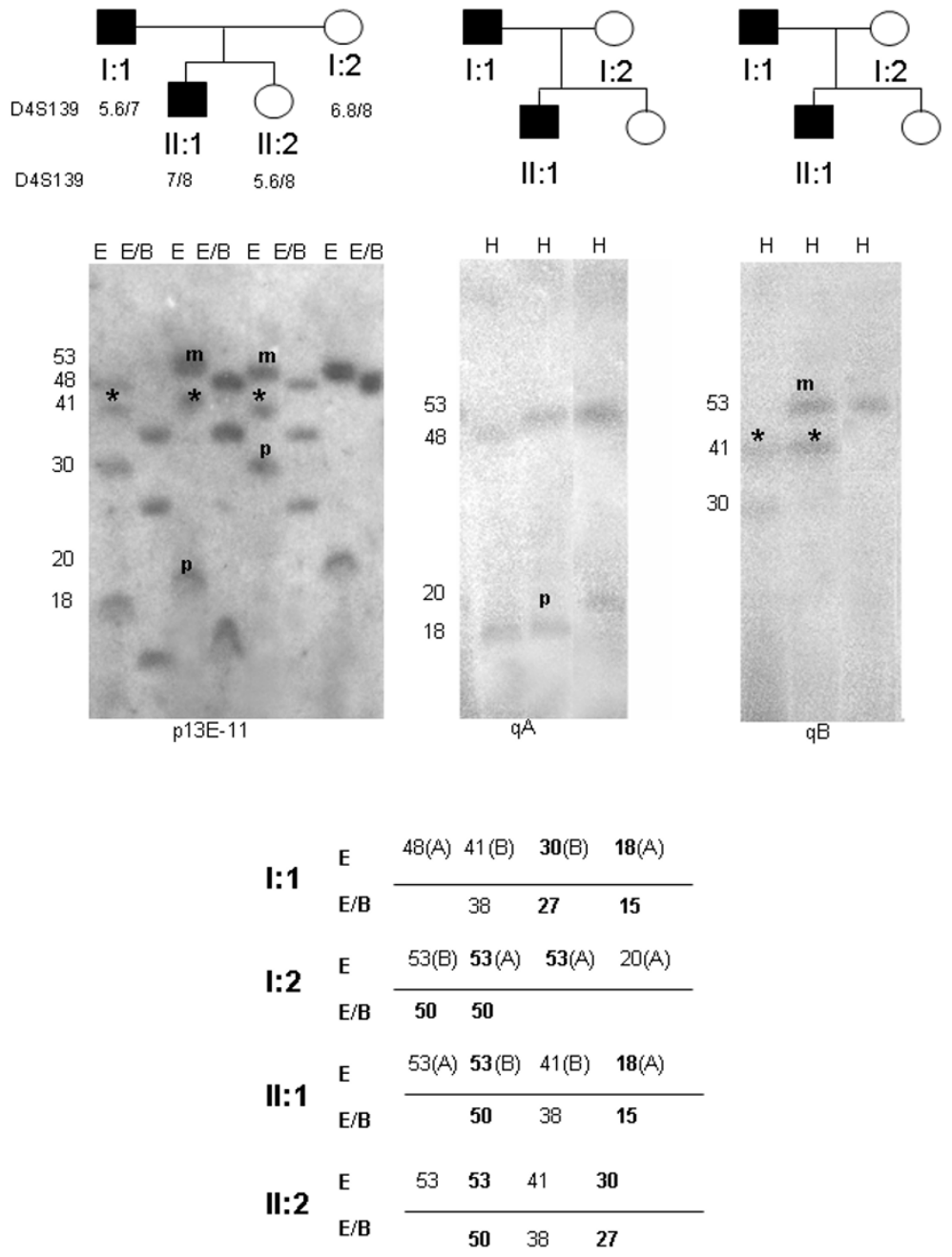

\section{Figure 3}

4q and I0q allelic pattern of a FSHD family after hybridization with p I $3 E-I$ I and $q A-q B$ telomeric markers. a) DNA samples were digested with EcoRI (E) and EcoRI/BInl (E/B) enzymes, separated with PFGE and hybridized with pI3E-II probe. The proband (I:I) shows a trisomic pattern with two $4 \mathrm{q}$ alleles of $\mathrm{I} 8$ and $30 \mathrm{~kb}$ and two $10 \mathrm{q}$ alleles of $4 \mathrm{I}$ (Blnl-resistant) $\left.{ }^{*}\right)$ and $48 \mathrm{~kb}$ (BInl-sensitive). The affected son (II:I) is also trisomic and inherited from the father the 4q FSHD allele of $18 \mathrm{~kb}$ and the $10 \mathrm{q}$ of $4 \mathrm{I} \mathrm{kb}\left(^{*}\right)$ and from the mother the $4 \mathrm{q}$ of $53 \mathrm{~kb}$ and a similar size $10 \mathrm{q}$ allele. The unaffected daughter inherited from the father the $4 \mathrm{q}$ allele of $30 \mathrm{~kb}$ and the $10 \mathrm{q}$ Blnl-resistant allele of $4 \mathrm{I} \mathrm{kb}(*)$ and from the mother the $4 \mathrm{q}$ and $10 \mathrm{q}$ fragments of $53 \mathrm{~kb}$. The segregation data for the probe D4SI39 showed that II:I and II:2 inherited the same 4q allele from the mother (l:2), but different $4 q$ alleles from the father (l:I). This suggest that the Blnl-resistant allele of $4 \mathrm{I} k \mathrm{k}$ is a $I 0 q$ variant; $b)$ DNA samples were digested with HindIII $(H)$, separated with PFGE and subsequently hybridized with $q A$ and $q B$ probes: the short $4 q$ allele $(18 \mathrm{~kb})$ is $q A$ type, while the $4 q$ allele of $30 \mathrm{~kb}$ is $q B$ type. All the standard $10 \mathrm{q}$ alleles of 48,53 and $20 \mathrm{~kb}$ have $\mathrm{qA}$ type telomeres, while the variant $\mathrm{IO} q$ allele of $4 \mathrm{I} \mathrm{kb}$ is $\mathrm{qB}$ type. This variant $\mathrm{IO} \mathrm{q}$ allele carries the BIn I-resistant repeat array and the distal telomeric sequence of $4 \mathrm{q}$-type. The $10 \mathrm{q}$ origin of this allele is confirmed by absence of segregation with D4SI39 probe. The DNA sample of the subject II: 2 was not sufficient for $\mathrm{qA} / \mathrm{qB}$ Southern Blot analysis and it was not included in figure 3. In the diagram below the alleles observed after EcoRI and EcoRI/BInl digestion are shown: the $4 q$ alleles are in bold and the telomeres $(\mathrm{A}$ or $\mathrm{B})$ are in brackets. 

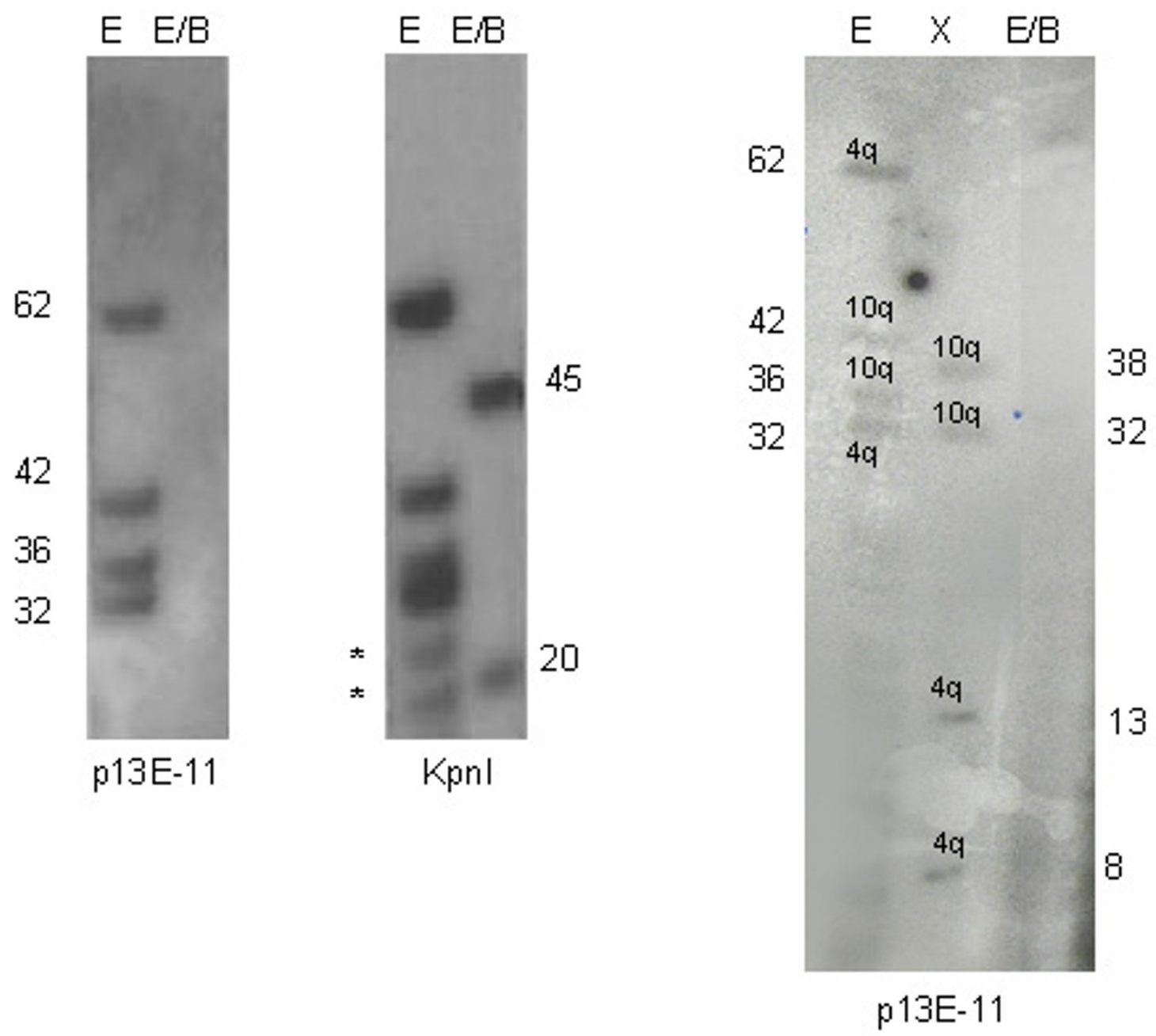

\section{Figure 4}

Nullisomic pattern. The patient shows four EcoRI bands after pI3E-I I hybridization and none after double digestion with EcoRI/BInl (nulisomic pattern). After hybridization with Kpnl probe two Blnl resistant band are visible (45 and $20 \mathrm{~kb})$ : we can not guess the chromosomal origin of these alleles. To resolve the structure of the alleles we digested the sample with Xapl enzyme which cuts the 4q-type repeats only (see Methods). After hybridization with pl 3E-I I we observed 4 Xapl-resistant bands $(38,32,13$ and $8 \mathrm{~kb})$ : the 38 and $32 \mathrm{~kb}$ bands correspond to the EcoRI fragments of 42 and $36 \mathrm{~kb}$ fragments (Xapl fragments are $4 \mathrm{~kb}$ smaller than EcoRI fragments). On the contrary the 13 and $8 \mathrm{~kb}$ fragments are stretches of the hybrid $4 \mathrm{q}$ alleles: the $62 \mathrm{~kb}$ EcoRI allele is composed by a BInl-sensitive fragment (Xapl-resistant) of I $3 \mathrm{~kb}$ and a Blnl-resistant fragment of $45 \mathrm{~kb}$ $(\mathrm{I} 3+45=58 \mathrm{~kb})$. The $32 \mathrm{~kb}$ EcoRI allele is composed by a Blnl-sensitive fragment (Xapl-resistant) of $8 \mathrm{~kb}$ and a Blnl-resistant fragment of $20 \mathrm{~kb}(8+20=28 \mathrm{~kb})$. The $4 \mathrm{q}$ variant alleles are represented in figure $5(\mathrm{n} .15 \mathrm{and} \mathrm{I6)}$. The FSHD $4 \mathrm{q}$ allele of $32 \mathrm{~kb}$ segregated also in other affected members of the family and its origin was confirmed by D4SI39 probe (data not shown). * aspecific bands. 

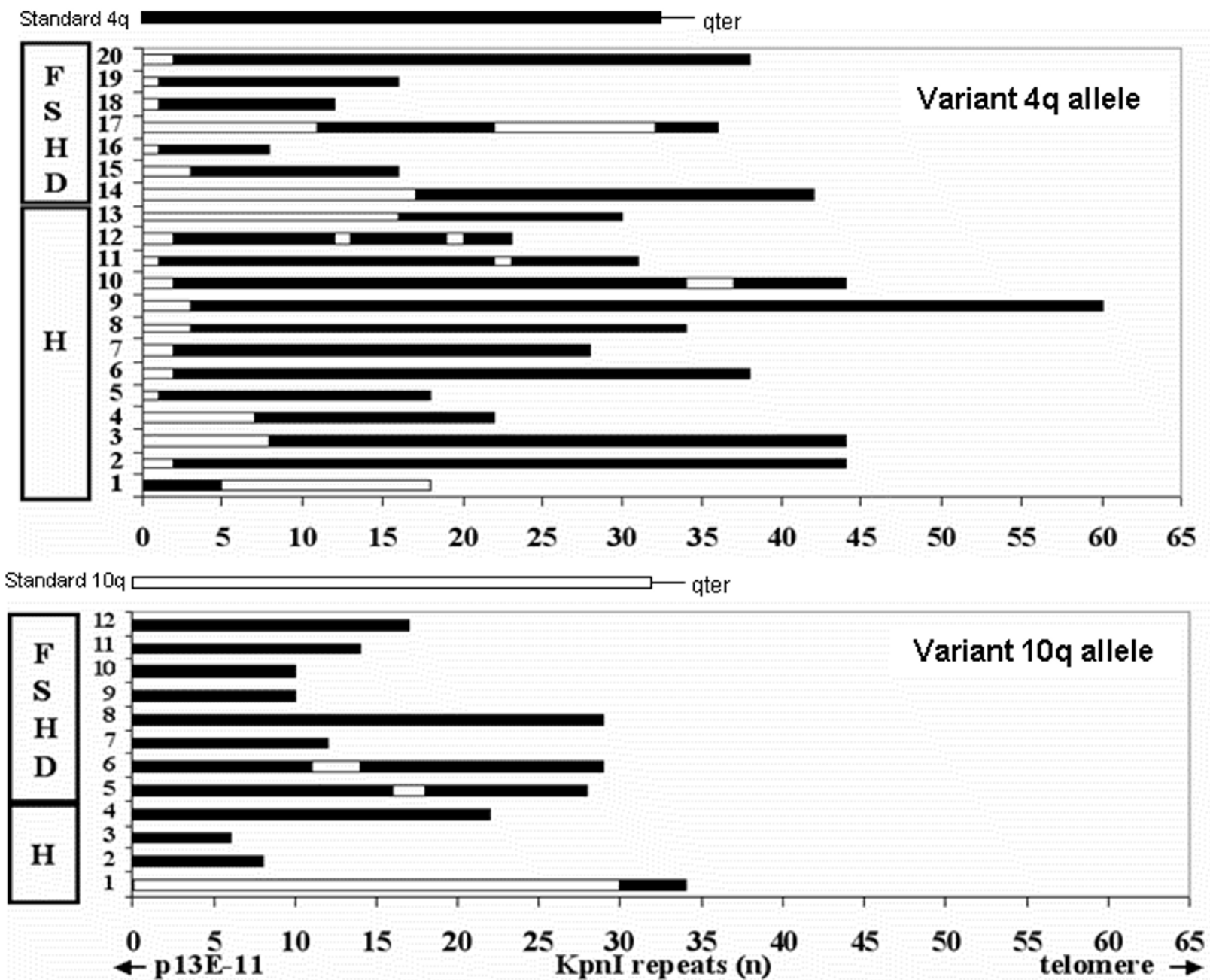

\section{Figure 5}

Analysis of structural organization of variant $4 q$ and $10 q$ alleles in healthy subjects and FSHD patients. White bars: BInl-sensitive repeats; Black bars: Blnl-resistant repeats. Variant $4 q$ alleles: $\mathrm{N}^{\circ} \mathrm{I}-\mathrm{I} 3$ refer to healthy subjects $(\mathrm{H}), \mathrm{N}^{\circ} \mathrm{I} 4-$ 20 to FSHD patients. Variant $10 q$ alleles: $\mathrm{N}^{\circ} \mathrm{I}-4$ refer to healthy subjects $(\mathrm{H}), \mathrm{N}^{\circ} 5-\mathrm{I} 2$ to FSHD patients.

Furthermore we studied in a different population the 4qter polymorphism distal to D4Z4 described in a previous Dutch study [17] and confirmed the FSHD association only with qA type sequence, but we also detected the presence of borderline alleles in the range of $30-40 \mathrm{~kb}$ of qA type, not associated with the disease. This suggests that other concomitant factors, either genetic or environmental, are implicated in the pathogenesis of the FSHD. It appears that the 4qA allele-typing is necessary but not sufficient to assign the pathogenic role to a $4 \mathrm{q}$ short allele.

\section{Abbreviations}

Facioscapulohumeral Muscular Dystrophy: FSHD

\section{Competing interests}

The author(s) declare that they have no competing interests.

\section{Authors' contributions}

MR performed laboratory work, results collection and wrote the paper. ER, GG and LF designed and coordinate the study. PAT recruited subjects and participated in clinical diagnosis, LC performed laboratory work and results collection. RF recruited subjects. LF supervised the study and wrote the paper.

All authors read and approved the final manuscript. 


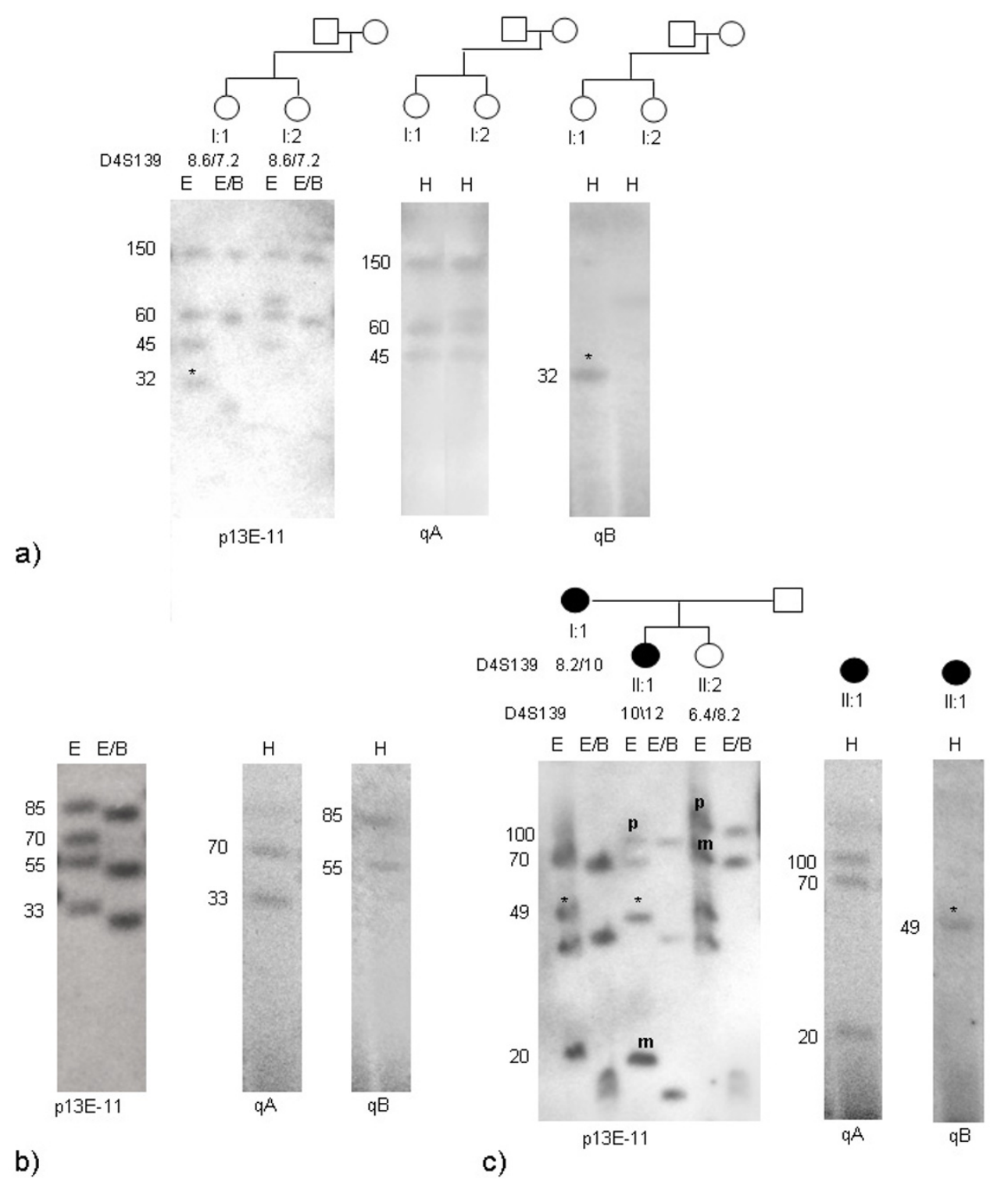

\section{Figure 6}

$10 q$ alleles with $q B$ telomere. Allelic pattern of individuals carrying $10 q$ alleles with a $q B$ type telomere. a) The segregation study with the D4SI 39 probe demonstrates that the two sisters inherited the same $4 \mathrm{q}$ alleles of 150 and $60 \mathrm{~kb}$. I:I shows a trisomic pattern with a Blnl-resistant 10q of $32 \mathrm{~kb}\left({ }^{*}\right)$ and a standard 10q of $45 \mathrm{~kb}$. The analysis of the telomeric sequences reveals that the variant $10 \mathrm{q}$ allele of $32 \mathrm{~kb}$ has a $\mathrm{qB}$ telomere. The two $4 \mathrm{q}$ alleles and the standard $10 \mathrm{q}$ allele of $45 \mathrm{~kb}$ have $\mathrm{qA}$ telomeres. b) The patient is trisomic and carries a FSHD allele of $33 \mathrm{~kb}$ and a standard $10 \mathrm{q}$ allele of $70 \mathrm{~kb}$ with a qA telomere. We can not distinguish the $10 q$ variant allele from the $4 q$ standard alleles. Since both the $85 \mathrm{~kb}$ and $55 \mathrm{~kb}$ show a $\mathrm{qB}$ telomere, we deduce that the variant $10 \mathrm{q}$ allele carries a $\mathrm{qB}$ telomere. $\mathrm{c}$ ) The $4 \mathrm{q}$ short allele of $20 \mathrm{~kb}$ segregates with FSHD in the family. The affected daughter (II:I) is trisomic and inherited from the mother (I:I) both the FSHD-linked 4q of $20 \mathrm{~kb}$ and the BInlresistant 10q allele of $49 \mathrm{~kb}\left(^{*}\right)$ and from the father a standard $10 \mathrm{q}$ allele of $70 \mathrm{~kb}$ and a $4 \mathrm{q}$ standard allele of $100 \mathrm{~kb}$. The analysis of the telomeric sequences shows that the variant $10 \mathrm{q}$ allele of $49 \mathrm{~kb}$ has a $\mathrm{qB}$ telomere, while the $10 \mathrm{q}$ standard allele of 70 $\mathrm{kb}$ and both $4 \mathrm{q}$ alleles of 100 and $70 \mathrm{~kb}$ have a $\mathrm{qA}$ telomere. The $10 \mathrm{q}$ variant allele of $49 \mathrm{~kb}$ is represented in figure 5 (n. I I). 


\section{Acknowledgements}

We are most grateful to Prof. Andrea Novelletto for the statistical analysis, Patrizia Venditti, Mario Pescatori and Silvere M. van der Maarel for helpful discussions. This work has been supported by Telethon Italy grant No. I296, by UILDM Rome Section, Italy and partially by Italian MIUR and Italian Ministry of Health.

\section{References}

I. Eichler EE: Masquerading repeats: paralogous pitfalls of the human genomes. Genome Res 1998, 8:758-762.

2. Kuryshev VY, Vorobyov E, Zink D, Schmitz J, Rozhdestvensky TS, Munstermann E, Ernst U, Wellenreuther R, Moosmayer P, Bechtel S, Schupp I, Horst J, Korn B, Poustka A, Wiemann S: An anthropoid specific segmental duplication on human chromosome Iq22. Genomics 2006, 88: |43-I5।.

3. Trask BJ, Massa H, Brand-Arpon V, Chan K, Friedman C, Nguyen OT, Eichler E, van den Engh G, Rouquier S, Shizuya H, Giorgi D: Large multi-chromosomal duplications encompass many members of the olfactory receptor gene family in the human genome. Hum Mol Genet 1998, 7:2007-2020.

4. Eichler EE, Budarf ML, Rocchi M, Deaven LL, Doggett NA, Baldini A, Nelson DL, Mohrenweiser HW: Interchromosomal duplications of the adrenoleuko-dystrophy locus: a phenomenon of pericentromeric plasticity. Hum Mol Genet 1997, 6:99I-1002.

5. Linardopoulou EV, Williams EM, Fan Y, Friedman C, Young JM, Trask $B$ ): Human subtelomeres are hot spots of interchromosomal recombination and segmental duplication. Nature 2006, 43:94-100.

6. van Geel M, Dickson MC, Beck AF, Bolland DJ, Frants RR, van der Maarel SM, de Jong PJ, Hewitt JE: A Cascade of Complex Subtelomeric Duplications during the Evolution of the Hominoid and Old World Monkey Genomes. Am J Hum Genet 2002, 70:269-278.

7. van Geel M, Dickson MC, Beck AF, Bolland DJ, Frants RR, van der Maarel SM, de Jong PJ, Hewitt JE: Genomic analysis of human chromosome $10 \mathrm{q}$ and $4 \mathrm{q}$ telomeres suggests a common origin. Genomics 2002, 79:210-217.

8. Deidda G, Cacurri S, Grisanti P, Vigneti E, Piazzo N, Felicetti L: Physical mapping evidence for a duplicated region on chromosome I Oqter showing high homology with the FSHD locus on chromosome 4qter. Eur J Hum Genet 1995, 3: I 55-167.

9. Sarfarazi M, Wijmenga C, Upadhyaya M, Weiffenbach B, Hyser C, Mathews K, Murray J, Gilbert J, Pericak-Vance M, Lunt P: Regional mapping of facioscapulohumeral muscular dystrophy gene on 4q35: combined analysis of an international consortium. Am J Hum Genet 1992, 5 I:396-403.

10. Wijmenga C, Hewitt JE, Sandkuijl LA, Clark LN, Wright TJ, Dauwerse HG, Gruter AM, Hofker MH, Moerer P, Williamson R: Chromosome 4q DNA rearrangements associated with facioscapulohumeral muscular dystrophy. Nat Genet 1992, 2:26-30.

II. Orrell RW, Tawil R, Forrester J, Kissel JT, Mendell JR, Figlewicz DA: Definitive molecular diagnosis of facioscapulohumeral dystrophy. Neurology 1999, 52:1822-1826.

12. Ricci E, Galluzzi G, Deidda G, Cacurri S, Colantoni L, Merico B, Piazzo N, Servidei S, Vigneti E, Pasceri V, Silvestri G, Mirabella M, Mangiola $\mathrm{F}$, Tonali $\mathrm{P}$, Felicetti L: Progress in the molecular diagnosis of facioscapulohumeral muscular dystrophy (FSHD) and correlation between the number of Kpnl repeats at the $4 q 35$ locus and clinical phenotype. Ann Neurol 1999, 45:75।-757.

13. Deidda G, Cacurri S, Piazzo N, Felicetti L: Direct detection of 4q35 rearrangements implicated in facioscapulohumeral muscular dystrophy (FSHD). J Med Genet 1996, 33:36 I-365.

14. Cacurri S, Piazzo N, Deidda G, Vigneti E, Galluzzi G, Colantoni L, Merico B, Ricci E, Felicetti L: Sequence homology between 4qter and IOqter loci facilitates the instability of subtelomeric Kpnl repeats units implicated in facioscapulohumeral muscular dystrophy. Am J Hum Genet 1998, 63:181-190.

15. van Overveld PG, Lemmers RJ, Deidda G, Sandkuijl L, Padberg GW, Frants RR, van Der Maarel SM: Interchromosomal repeat array interactions between chromosomes 4 and 10: a model for subtelomeric plasticity. Hum Mol Genet 2000, 9:2879-2884.

16. Lemmers RJ, van der Maarel SM, van Deutekom JC, van der Wielen MJ, Deidda G, Dauwerse HG, Hewitt J, Hofker M, Bakker E, Padberg $\mathrm{GW}$, Frants RR: Inter- and intrachromosomal sub-telomeric rearrangements on 4q35: implications for facioscapulohumeral muscular dystrophy (FSHD) aetiology and diagnosis. Hum Mol Genet 1998, 7:1207-I214.

17. Lemmers RJ, de Kievit P, Sandkuijl L, Padberg GW, van Ommen G], Frants RR, van der Maarel SM: Facioscapulohumeral muscular dystrophy is uniquely associated with one variants of $4 q$ subtelomere. Nat Genet 2002, 32:235-236.

18. Lemmers RJ, Wohlgemuth M, Frants RR, Padberg GW, Morava E, van der Maarel SM: Contraction of D4Z4 on 4qB subtelomere do not cause Facioscapulohumeral muscular dystrophy. Am J Hum Gen 2004, 75: I I 24- I I 30.

19. Padberg GW, Lunt PW, Koch M, Fardeau M: Diagnostic criteria for facioscapulohumeral muscular dystrophy. Neuromuscul Disord 1991, I:231-234.

20. Felicetti L, Galluzzi G: Pulse field gel electrophoresis for the detection of facioscapulohumeral muscular dystrophy gene rearrangements. In Methods in Molecular Biology: Neurogenetics: Methods and Protocols Volume 217. PotterCHumana Press Inc, Totowa, NJ; 2003: I53-164.

21. Cacurri S, Deidda G, Piazzo N, Novelletto A, La Cesa I, Servidei S, Galluzzi G, Wijmenga C, Frants RR, Felicetti L: Chromosome 4q35 haplothypes and DNA rearrangements segregating in affected subjects of 19 Italian families with Facioscapulohumeral muscular dystrophy (FSHD). Hum Genet 1994, 94:367-374.

22. Wijmenga $C$, van Deutekom JCT, Hewitt JE, Padberg GW, van Ommen GB, Hofker MH, Frants RR: Pulsed-field gel electrophoresis of the D4FI04SI locus reveals the size and the parental origin of the facioscapulohumeral muscular dystrophy (FSHD)-associated deletions. Genomics 1994, 19:2 I-26.

23. Lemmers RJL, vanOverveld PGM, Sandkuij A, Vrieling H, Padberg GW, Frants RR, vanderMaarel SM: Mechanism and timing of mitotic rearrangements in the subtelomeric $D 4 Z 4$ repeat involved in facioscapulohumeral muscular dystrophy. Am J Hum Genet 2004, 75:44-53.

24. Wohlgemuth M, Lemmers RJ, van der Kooi EL, van der Wielen MJ, van Overveld PG, Dauwerse H, Bakker E, Frants RR, Padberg GW, van der Maarel SM: Possible phenotypic dosage effect in patients compound heterozygous for FSHD-sized 4q35 alleles. Neurology 2003, 6 I:909-9I3.

25. Tupler R, Berardinelli A, Barbierato L, Frants R, Hewitt JE, Lanzi G, Maraschio P, Tiepolo L: Monosomy of distal 4q does not cause facioscapulohumeral muscular dystrophy. J Med Genet 1996, 33:366-370.

26. Goto K, Lee JH, Matsuda C, Hirabayashi K, Kojo T, Nakamura A, Mitsunaga Y, Furukawa T, Sahashi KO, Arahata K: DNA rearrangements in Japanese facioscapulohumeral muscular dystrophy patients: clinical correlations. Neuromuscul Disord 1995 , 5:201-208.

27. Lemmers RJL, de Kievit P, van Geel M, van der Wielen MJ, Bakker E, Padberg GW, Frants RR, van der Maarel SM: Complete allele information in the diagnosis of facioscapulohumeral muscular dystrophy by triple DNA analysis. Ann Neurol 200I, 50:816-8I9.

28. Gabellini D, Green MR, Tupler R: Inappropriate gene activation in FSHD: a repressor complex binds a chromosomal repeat deleted in dystrophic muscle. Cell 2002, I I 0:339-348.

29. Gabellini D, D'Antona G, Moggio M, Prelle A, Zecca C, Adami R, Angeletti B, Ciscato P, Pellegrino MA, Bottinelli R, Green MR, Tupler $\mathrm{R}$ : Facioscapulohumeral muscular dystrophy in mice overexpressing FRGI. Nature 2006, 439:73-77.

\section{Pre-publication history}

The pre-publication history for this paper can be accessed here:

http://www.biomedcentral.com/1471-2350/8/8/prepub 